\title{
Height and sex is strongly associated with radial augmentation index in Korean patients with never-treated hypertension
}

\author{
Kye Taek Ahn \\ Kwang-In Park \\ Mi Joo Kim \\ Jin Kyung Oh \\ Ji Hye Han \\ Hee Jin Kwon \\ Seon-Ah Jin \\ Jun-Hyung Kim \\ Jae-Hyeong Park \\ Jae-Hwan Lee \\ Si Wan Choi \\ In-Whan Seong \\ Jin-Ok Jeong
}

Department of Internal Medicine, Division of Cardiology, Chungnam National University Hospital,

Chungnam National University

School of Medicine, Daejeon,

Republic of Korea
This article was published in the following Dove Press journal:

Clinical Interventions in Aging

II April 2016

Number of times this article has been viewed

Objectives: Central hemodynamics may better represent the load imposed on the coronary and cerebral arteries and thereby bear a stronger relationship to cardiovascular outcomes.

Methods: Patients who had confirmed hypertension as assessed by daytime 24-hour ambulatory blood pressure monitoring ( $\geq 135 / 85 \mathrm{mmHg}$ ) were enrolled. Central blood pressure and radial augmentation index (AIx) corrected for a heart rate of $75 \mathrm{bpm}$ (radial AIx 75) were measured for all patients. We evaluated the association of age, height, and sex with central hemodynamics in patients with never-treated hypertension.

Results: A total of 203 patients were enrolled, of whom men numbered 101 (49.7\%). The median height of all patients was $162 \mathrm{~cm}$, and mean age was 53.2 years. In the Pearson correlation analysis, regardless of sex difference ( $R=-0.627$ for height, $R=0.035$ for age, $P$-value $=0.005$ ), a stronger relationship was observed between height and radial AIx 75 than between age and radial AIx 75. In the multiple regression analysis, the sex difference and height were strongly associated with elevated radial AIx 75 in all patients (adjusted $R^{2}=0.428, \beta=6.237,95 \%$ confidence interval [CI] for women $1.480-10.995, P$-value $=0.011$ and $\beta=-0.632,95 \%$ CI for height -0.929 to $-0.335, P$-value $=0.009$, respectively).

Conclusion: In patients with never-treated hypertension, female sex and shorter height are the important risk factors of elevated radial AIx 75.

Keywords: hypertension, augmentation index, height, sex

\section{Introduction}

Central hemodynamics could better explain the load imposed on the coronary and cerebral arteries and thereby bear a stronger relationship to cardiovascular outcomes than brachial blood pressure (BP) does. ${ }^{1,2}$

Augmentation index (AIx) can be easily and noninvasively recorded by radial applanation tonometry and is well-known as an important predictor of cardiovascular events and all-cause mortality over brachial BP parameter. ${ }^{1,2}$ It is well-known that radial AIx is strongly correlated with aortic AIx. ${ }^{3}$

Arterial stiffness and early wave reflections lead to the augmentation of central aortic pressure wave amplitude, and height would be inversely related to AIx. Several studies showed that height is inversely related to the risk of cardiovascular disease. ${ }^{4-8}$ It was initially reported in 1951 by Gertler et al, ${ }^{9}$ and has since been repeatedly reported in the recent era also. A recent large study reported that height is inversely and independently related to central hemodynamics, including AIx. ${ }^{10}$ However, most of these results are derived from patients with established disease (ie, hypertension, end-stage renal disease, or coronary artery disease), and conflicting opinions that the increased
Correspondence: Jin-Ok Jeong

Division of Cardiology, Chungnam

National University Hospital, Chungnam

National University School of Medicine,

282 Munhwa-ro, Jung-gu, Daejeon 35015,

Republic of Korea

Tel +82422808227

Fax +82422808238

Email jojeong@cnu.ac.kr
Clinical Interventions in Aging 2016: I | 4I5-422

415

Dovepres:

http://dx.doi.org/10.2147/CIA.SI0|302 (c) (1) (2) 2016 Ahn et al. This work is published and licensed by Dove Medical Press Limited. The full terms of this license are available at https://www.dovepress.com/terms.php
and incorporate the Creative Commons Attribution - Non Commercial (unported, v3.0) License (http:///creativecommons.org/licenses/by-nc/3.0/). By accessing the work you BY NC and incorporate the Creative Commons Attribution - Non Commercial (unported, v3.0) License (http://creativecommons.org/licenses/by-nd $3.0 /$ ). By accessing the work you
hereby accept the Terms. Non-commercial uses of the work are permitted without any further permission from Dove Medical Press Limited, provided the work is properly attributed. For permission hereby accept the Terms. Non-commercial uses of the work are permitted without any further permission from Dove Medice
for commercial use of this work, please see paragraphs 4.2 and 5 of our Terms (https://www.dovepress.com/terms.php). 
central hemodynamics were strongly related to sex and aging than lower height exist. ${ }^{10-14}$

Therefore, we evaluated the association between central hemodynamics and age, height, and sex in patients with never-treated hypertension.

\section{Patients and methods}

\section{Study population}

Between August 2011 and July 2014, a total of 203 patients were retrospectively enrolled in the Chungnam National University Hospital. Enrolled patients were diagnosed with hypertension by daytime 24-hour ambulatory blood pressure monitoring (ABPM; $\geq 135 / 85 \mathrm{mmHg}$ ) and had no experience of taking antihypertensive agents. The study was approved by the Institutional Review Board of Chungnam National University Hospital. This study was exempt from written informed consent due to the fact that it was a retrospective study.

\section{Methods and definitions}

Multiple measurements of the out-of-office brachial BP were obtained from the oscillometric ABPM recorders (TONOPORT V, GM Medical System, Berlin, Germany; Mobil-O-Graph new generation, I.E.M., Stolberg, Germany), as previously validated. ${ }^{15,16}$ Central BPs and radial AIx were noninvasively measured by using a validated device (HEM-9000AI, Omron Healthcare, Kyoto, Japan), ${ }^{17}$ while the patient was made to sit on the prepared chair with the cuff wrapped around the upper part of patient's right arm and the aortic insufficiency pulse wave sensor unit placed on the radial artery of patient's left wrist. Central systolic BP (SBP), diastolic BP (DBP), pulse pressure (PP), augmentation pressure, and radial AIx were measured using the technique of pulse waveform analysis. PP was calculated as the difference between respective systolic and diastolic pressure. Radial AIx was calculated as follows: (second peak SBP2 - DBP)/ (first peak SBP - DBP) $\times 100(\%)$. In addition, given that the AIx is influenced by heart rate, the index was corrected for a heart rate of $75 \mathrm{bpm}$. PP amplification was calculated as the ratio of the peripheral to central $\mathrm{PP}$, in percentage, as well.

Early-morning BP was defined as the average of BP readings taken 2 hours after waking up. Early-morning BP surge (EMBPS) was defined as the difference of the mean earlymorning SBP and the lowest night SBP. Recorders were programmed to measure brachial BP at 30-minute intervals during the daytime (from 7 am to $10 \mathrm{pm}$ ) and at 60-minute intervals during the nighttime (from $10 \mathrm{pm}$ to $7 \mathrm{am}$ ). Degree of dipping was calculated as 1 minus the ratio of daytime mean SBP to nighttime mean SBP and was presented in percentage.
Height and weight were measured along with central BP measurement. Height was measured with each participant's head in the Frankfurt plane to the nearest $0.1 \mathrm{~cm}$ by using a DS-102 apparatus (Dong Shan JENIX Co. Ltd., Seoul, Republic of Korea), and body mass index (BMI) was calculated as weight in kilograms divided by height in meters squared.

\section{Statistical analysis}

This study is a cross-sectional study. Continuous variables were expressed as the mean \pm standard deviation and then were compared using the independent Student's $t$-test. Statistical significances were also tested by one-way analysis of variance (ANOVA) combined with Tukey's post hoc analysis. Categorical variables were compared with Pearson's chi-square or Fisher's exact tests and were presented as absolute and relative frequencies (\%). Pearson's simple correlation analyses were performed to determine the association between AIx and height and age. Differences between the slopes association of AIx 75 with height and age were assessed by Pearson's correlation and Hotelling test. Differences between the slopes association of radial AIx 75 with height and age of men and women were assessed by Pearson's correlation using Fisher's Z-transformation. Simple linear regression analysis was performed to determine the independent association of radial AIx 75 with clinical variables and hemodynamic parameters. The following variables were included in the multivariate analysis when they were available from all patients and were significantly related to radial AIx 75 on univariate analysis: age, height, sex, diabetes mellitus (DM), smoker, high density lipoprotein (HDL), 24hr-ABPM day SBP, 24hr-ABPM mean heart rate (HR), and EMBPS.

\section{Results}

\section{Baseline characteristics according to sex and height}

A total 203 patients were enrolled. The median height of all patients was $162 \mathrm{~cm}$. The data in Table 1 shows the comparison between the clinical variables according to the sex. Height and BMI were significantly lower in women. Although blood urea nitrogen and creatinine were significantly different in both groups, they were in the normal range. The incidence of smoking was lower in women. The shorter height group was defined as a group with height less than median value and the taller height group was defined as a group with height more than median value. When the clinical variables were compared according to the median height in each sex, the shorter height group was found to be older in both men and women, but BMI was increased only in taller 
Table I Baseline clinical characteristics according to the sex and height

\begin{tabular}{|c|c|c|c|c|}
\hline Variables & All patients $(n=203)$ & Men $(n=10 I)$ & Women $(n=102)$ & $P$-value \\
\hline Age (years) & $53.2 \pm 11.6$ & $52.4 \pm \mid 3.1$ & $54.1 \pm 9.8$ & 0.294 \\
\hline Height (cm) & $163.4 \pm 8.8$ & $169.5 \pm 6.8$ & $157.3 \pm 5.8$ & $<0.001$ \\
\hline BMI $\left(\mathrm{kg} / \mathrm{m}^{2}\right)$ & $25.6 \pm 3.3$ & $26.2 \pm 3.3$ & $25.2 \pm 3.5$ & 0.027 \\
\hline Smoker (\%) & $20(9.9)$ & $18(17.8)$ & $2(1.9)$ & 0.001 \\
\hline DM (\%) & $21(10.3)$ & $12(11.9)$ & $9(8.8)$ & 0.499 \\
\hline BUN (mg/dL) & $14.4 \pm 4.9$ & $15.6 \pm 5.4$ & $13.2 \pm 4 . \mid$ & 0.005 \\
\hline Creatinine (mg/dL) & $0.8 I \pm 0.22$ & $0.94 \pm 0.19$ & $0.66 \pm 0.13$ & $<0.001$ \\
\hline Total cholesterol (mg/dL) & $189.3 \pm 39.1$ & $186.5 \pm 39.1$ & $192.1 \pm 39.1$ & 0.328 \\
\hline Triglycerides (mg/dL) & $157.9 \pm 98.6$ & $169.6 \pm 93.9$ & $145.3 \pm 102.3$ & 0.101 \\
\hline $\mathrm{HDL}(\mathrm{mg} / \mathrm{dL})$ & $52.3 \pm 14.5$ & $48.1 \pm 11.7$ & $56.9 \pm 15.8$ & $<0.001$ \\
\hline LDL (mg/dL) & $117.4 \pm 33.5$ & $114.4 \pm 33.7$ & $120.8 \pm 33.2$ & 0.245 \\
\hline
\end{tabular}

Note: Data presented as mean \pm standard deviation.

Abbreviations: BMI, body mass index; DM, diabetes mellitus; BUN, blood urea nitrogen; HDL, high-density lipoprotein; LDL, low-density lipoprotein.

height group of men. Other than age and BMI, no other difference was observed between shorter height group and taller height group in both sexes (Table 2).

\section{Hemodynamic characteristics according to sex and height}

When the 24-hour ABPM data and central BP were compared according to the median height in each sex, radial AIx 75 and central PP were elevated in the shorter height group in both sexes. However, the 24-hour ABPM parameters showed no difference between shorter height group and taller height group in men, except EMBPS and morning mean SBP. In women, only 24-hour ABPM DBP parameters were elevated in taller height group, but the other parameters showed no differences between shorter height group and taller height group (Table 3).

\section{Relationship between height and central hemodynamics}

In the one-way ANOVA, as the quartile of height increases with statistical significance, radial AIx 75 showed a gradually decreasing tendency (Figure 1). Radial AIx 75 was inversely correlated with height but was positively correlated with age in Pearson's correlation analysis (Figure 2). In the Pearson correlation and Hotelling test, the slope of the association between height and radial AIx 75 was significantly stronger than the slope of the association between age and radial AIx 75 (Pearson $R=-0.627$ for height and 0.035 for age, $P$-value $=0.005$; Figure 2A and D). In Pearson's correlation analysis using Fisher's Z-transformation, the slope of the association between height and radial AIx 75 showed no difference between men and women (Pearson $R=-0.539$ for men and -0.309 for women, $P$-value $=0.222$; Figure $2 \mathrm{~B}$ and $\mathrm{C}$ ). The slope of the association between age and radial AIx 75, however, was significantly stronger in men (Pearson $R=0.450$ for men and 0.198 for women, $P$-value $=0.043$; Figure $2 \mathrm{E}$ and $\mathrm{F}$ ). A statistically significant association with the radial AIx 75 in multiple regression analysis was observed in all patients and according to sex difference (Table 4). Each model included traditional cardiovascular risk factors or variables that showed significant association in simple linear regression

Table 2 Baseline clinical characteristics between men and women, stratified by median height

\begin{tabular}{|c|c|c|c|c|c|c|}
\hline \multirow[t]{2}{*}{ Variables } & \multicolumn{2}{|l|}{ Men } & \multirow[t]{2}{*}{$P$-value } & \multicolumn{2}{|l|}{ Women } & \multirow[t]{2}{*}{$P$-value } \\
\hline & Shorter height $(n=48)$ & Taller height $(n=53)$ & & Shorter height $(n=48)$ & Taller height $(n=54)$ & \\
\hline Age (years) & $59.1 \pm 12.4$ & $46.2 \pm 10.5$ & $<0.001$ & $58.7 \pm 8.3$ & $49.9 \pm 9.1$ & $<0.001$ \\
\hline BMI $\left(\mathrm{kg} / \mathrm{m}^{2}\right)$ & $25.5 \pm 2.8$ & $26.7 \pm 3.1$ & 0.038 & $25.2 \pm 1.9$ & $25.1 \pm 4.5$ & 0.858 \\
\hline Smoker (\%) & $5(10)$ & $13(24.5)$ & 0.074 & $6(12.5)$ & $3(5.5)$ & 0.300 \\
\hline $\mathrm{DM}(\%)$ & $9(18.8)$ & $3(5.7)$ & 0.063 & I (2) & I (I.8) & 0.999 \\
\hline BUN (mg/dL) & $16.8 \pm 5.8$ & $14.0 \pm 4.6$ & 0.028 & $13.4 \pm 4.2$ & $13.1 \pm 4 . \mid$ & 0.721 \\
\hline Creatinine (mg/dL) & $0.97 \pm 0.23$ & $0.91 \pm 0.13$ & 0.180 & $0.66 \pm 1.9$ & $0.66 \pm 0.13$ & 0.884 \\
\hline Total cholesterol (mg/dL) & $184.7 \pm 47.4$ & $188.2 \pm 29.6$ & 0.662 & $185.9 \pm 42.7$ & $198.0 \pm 34.9$ & 0.139 \\
\hline Triglycerides (mg/dL) & $167.8 \pm 106.7$ & $|7| .4 \pm 80.3$ & 0.858 & $\mid 43.8 \pm 89.2$ & $|46.8 \pm| \mid 5.0$ & 0.897 \\
\hline $\mathrm{HDL}(\mathrm{mg} / \mathrm{dL})$ & $46.8 \pm 12.4$ & $49.3 \pm 10.9$ & 0.336 & $54.6 \pm 15.1$ & $58.7 \pm 16.4$ & 0.258 \\
\hline LDL (mg/dL) & I I $2.7 \pm 37.6$ & $1 \mid 6.1 \pm 29.8$ & 0.660 & $119.7 \pm 34.7$ & $121.6 \pm 32.5$ & 0.813 \\
\hline
\end{tabular}

Notes: Data presented as mean \pm standard deviation. The median height was $169 \mathrm{~cm}$ in men and $157 \mathrm{~cm}$ in women. The shorter height group was defined as a group of less than median height and the taller height group was defined as a group of more than median height.

Abbreviations: BMI, body mass index; DM, diabetes mellitus; BUN, blood urea nitrogen; HDL, high-density lipoprotein; LDL, low-density lipoprotein. 
Table 3 Twenty-four-hour ABPM parameters and central, peripheral (brachial) blood pressure stratified by median height of each sex

\begin{tabular}{|c|c|c|c|c|c|c|}
\hline \multirow[t]{2}{*}{ Variables } & \multicolumn{2}{|l|}{ Men } & \multirow[t]{2}{*}{$P$-value } & \multicolumn{2}{|l|}{ Women } & \multirow[t]{2}{*}{$P$-value } \\
\hline & Shorter height $(n=48)$ & Taller height $(n=53)$ & & Shorter height $(n=48)$ & Taller height $(n=54)$ & \\
\hline \multicolumn{7}{|l|}{ ABPM parameters } \\
\hline \multicolumn{7}{|l|}{ 24-hour ABPM } \\
\hline Mean SBP (mmHg) & $149.6 \pm|| .4$ & $149.0 \pm 9.8$ & 0.775 & $|4| .5 \pm 9.8$ & $145.2 \pm 13.6$ & 0.118 \\
\hline Mean DBP $(\mathrm{mmHg})$ & $96.2 \pm 9.6$ & $98.8 \pm 11.2$ & 0.208 & $90.3 \pm 7.8$ & $95.6 \pm 8.8$ & 0.002 \\
\hline Mean PP (mmHg) & $53.5 \pm 8.7$ & $50.2 \pm 7.8$ & 0.051 & $51.3 \pm 8.8$ & $49.7 \pm 8.4$ & 0.366 \\
\hline Mean HR (beats/min) & $71.3 \pm 9.6$ & $74.4 \pm 8.5$ & 0.093 & $71.9 \pm 10.2$ & $73.5 \pm 8.2$ & 0.381 \\
\hline \multicolumn{7}{|l|}{ Day-time ABPM } \\
\hline Mean SBP $(\mathrm{mmHg})$ & $152.0 \pm 1 \mid .7$ & $15 \mid .3 \pm 9.9$ & 0.760 & $144.7 \pm 9.9$ & $|47.9 \pm| 4.3$ & 0.192 \\
\hline Mean DBP (mmHg) & $98.6 \pm 10.2$ & $100.9 \pm 10.1$ & 0.268 & $92.8 \pm 8.3$ & $97.9 \pm 9.4$ & 0.004 \\
\hline Mean PP (mmHg) & $53.4 \pm 8.3$ & $50.5 \pm 6.5$ & 0.051 & $51.8 \pm 9.3$ & $49.9 \pm 8.5$ & 0.280 \\
\hline \multicolumn{7}{|l|}{ Night-time ABPM } \\
\hline Mean SBP (mmHg) & $141.3 \pm 14.5$ & $138.8 \pm \mid 4.9$ & 0.397 & $13 \mid .3 \pm 13.8$ & $|36.4 \pm| 4.6$ & 0.076 \\
\hline Mean DBP $(\mathrm{mmHg})$ & $88.7 \pm 10.6$ & $89.2 \pm 12.9$ & 0.827 & $82.5 \pm 8.9$ & $86.9 \pm 9.6$ & 0.016 \\
\hline Mean PP $(\mathrm{mmHg})$ & $52.6 \pm 10.7$ & $49.6 \pm 6.9$ & 0.102 & $48.9 \pm 9.7$ & $49.4 \pm 8.9$ & 0.769 \\
\hline \multicolumn{7}{|l|}{ Early morning } \\
\hline Mean SBP (mmHg) & $153.0 \pm 13.1$ & $147.2 \pm \mid 5.1$ & 0.043 & $146.5 \pm 14.4$ & $|48.3 \pm| 8.1$ & 0.578 \\
\hline Mean DBP $(\mathrm{mmHg})$ & $93.4 \pm 11.8$ & $92.3 \pm 13.5$ & 0.670 & $87.7 \pm 12.9$ & $91.9 \pm 10.7$ & 0.074 \\
\hline Mean PP $(\mathrm{mmHg})$ & $52.9 \pm 12.3$ & $49.0 \pm 10.6$ & 0.085 & $49.1 \pm 10.1$ & $49.5 \pm 12.4$ & 0.874 \\
\hline Mean HR (beats/min) & $69.8 \pm 23.0$ & $68.0 \pm 10.2$ & 0.600 & $70.2 \pm 17.7$ & $66.7 \pm 10.3$ & 0.220 \\
\hline EMBPS (mmHg) & $33.5 \pm 17.8$ & $26.9 \pm 14.1$ & 0.040 & $35.0 \pm 18.7$ & $29.1 \pm 15.4$ & 0.083 \\
\hline Degree of dipping (\%) & $6.9 \pm 7.3$ & $8.3 \pm 7.2$ & 0.342 & $9.2 \pm 7.8$ & $7.6 \pm 7.1$ & 0.296 \\
\hline \multicolumn{7}{|c|}{ Peripheral (brachial) } \\
\hline Mean SBP $(\mathrm{mmHg})$ & $153.9 \pm 20.8$ & $154.7 \pm \mid 5.6$ & 0.827 & $145.7 \pm|7|$. & $|50.1 \pm| 7.7$ & 0.200 \\
\hline Mean DBP $(\mathrm{mmHg})$ & $100.8 \pm 16.7$ & $103.4 \pm 13.2$ & 0.394 & $94.2 \pm 13.2$ & $101.3 \pm 12.7$ & 0.007 \\
\hline Mean PP $(\mathrm{mmHg})$ & $53.1 \pm 14.2$ & $51.4 \pm 11.2$ & 0.491 & $51.5 \pm 9.9$ & $48.8 \pm 11.2$ & 0.209 \\
\hline \multicolumn{7}{|l|}{ Central } \\
\hline Mean SBP $(\mathrm{mmHg})$ & $153.1 \pm 22.3$ & $142.1 \pm 15.4$ & 0.005 & $155.6 \pm 18.3$ & $153.1 \pm 19.9$ & 0.508 \\
\hline Mean DBP $(\mathrm{mmHg})$ & $86.6 \pm 11.1$ & $90.5 \pm 12.3$ & 0.098 & $86.9 \pm 13.4$ & $92.7 \pm 11.8$ & 0.024 \\
\hline Mean PP $(\mathrm{mmHg})$ & $66.5 \pm 20.7$ & $51.6 \pm 10.9$ & $<0.001$ & $68.7 \pm 16.4$ & $60.4 \pm 13.4$ & 0.006 \\
\hline Alx (\%) & $81.4 \pm 15.4$ & $67.1 \pm 12.7$ & $<0.001$ & $88.7 \pm 12.3$ & $84.0 \pm 10.9$ & 0.045 \\
\hline Alx 75 (\%) & $80.5 \pm 12.7$ & $67.7 \pm 10.6$ & $<0.001$ & $89.1 \pm 9.4$ & $85.0 \pm 8.9$ & 0.027 \\
\hline PP amplification & $94.9 \pm 13.2$ & $106.5 \pm 16.9$ & $<0.001$ & $87.7 \pm 10.4$ & $87.7 \pm 8.6$ & 0.967 \\
\hline
\end{tabular}

Notes: Data presented as mean \pm standard deviation. The median height was $169 \mathrm{~cm}$ in men and $157 \mathrm{~cm}$ in women. The shorter height group was defined as a group of less than median height and the taller height group was defined as a group of more than median height.

Abbreviations: ABPM, ambulatory blood pressure monitoring; SBP, systolic blood pressure; DBP, diastolic blood pressure; PP, pulse pressure; HR, heart rate; EMBPS, early-morning blood pressure surge; Alx, augmentation index.

analysis $(P$-value $<0.05$; Table 5$)$. The global $R^{2}$ is 0.428 in all patients and is 0.280 in men and 0.154 in women. Associated variables were age $(\beta$ coefficient $=0.232 ; 95 \%$ confidence interval $[\mathrm{CI}]=0.060-0.404 ; P$-value $=0.009)$ and female $\operatorname{sex}(\beta$ coefficient $=6.237 ; 95 \% \mathrm{CI}=1.480-10.995 ; P$-value $=0.011)$, showing that these factors had adverse effect on elevation of AIx 75 in all patients. Taller height $(\beta$ coefficient $=-0.632$; $95 \% \mathrm{CI}=-0.929$ to $-0.335 ; P$-value $<0.001)$ was related to decrease of radial AIx 75. The radial AIx 75 was significantly associated with age $(\beta$ coefficient $=0.296 ; 95 \% \mathrm{CI}=0.054$ $0.538 ; P$-value $<0.017)$ and height $(\beta$ coefficient $=-0.789$; $95 \% \mathrm{CI}=-1.247$ to $-0.330 ; P$-value $=0.001)$ in $\mathrm{men}$, and with height $(\beta$ coefficient $=-0.396 ; 95 \% \mathrm{CI}=-0.782$ to -0.011 ; $P$-value $=0.44)$ in women.

\section{Discussion}

The main finding of our study is that the height, sex, and age are strongly correlated with radial AIx 75 in patients with never-treated hypertension; the radial AIx 75 was significantly associated with age and height in men. However, only height was associated with radial AIx 75 in women.

Elevated arterial stiffness is a strong prognostic marker for cardiovascular mortality. Previously, several studies evaluated whether various central hemodynamics could predict cardiovascular events. ${ }^{12,18,19}$ Roman et $\mathrm{al}^{19}$ reported that noninvasively determined central PP is more strongly related to vascular hypertrophy, extent of atherosclerosis, and cardiovascular events than to brachial BP. ${ }^{19}$ Recent meta-analysis showed central hemodynamics including 


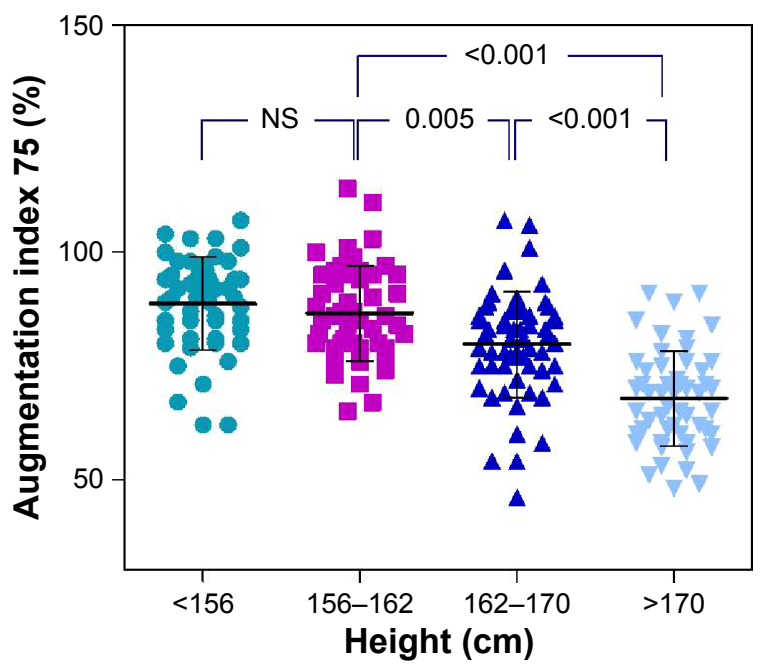

Figure I Statistical significances were tested by one-way ANOVA combined with Tukey's post hoc analysis among four height groups.

Notes: Data are expressed as the mean \pm SD. Alx 75 was significantly decreased in the group of $162 \mathrm{~cm}$ or higher compared with the group of $162 \mathrm{~cm}$ or less.

Abbreviations: NS, nonsignificant; ANOVA, analysis of variance; SD, standard deviation; Alx 75, augmentation index 75 .

AIx and central SBP and PP are important predictive values of CV events. Among these central hemodynamics, only AIx is a predictive value of all-cause mortality in a wide variety of the population. ${ }^{2}$ Elevated central hemodynamics is known to be strongly related to aging process, sex, and low stature. ${ }^{10,13,14,20}$ However, there are some conflicting opinions about the importance of these factors in affecting central hemodynamics. Shim et a ${ }^{13}$ reported that women had more elevated central hemodynamics compared to men; the elevation of central hemodynamics and the change of diastolic function are mainly due to sex difference rather than height, although height was significantly lower in women than in men. Mitchell et a ${ }^{14}$ also evaluated the relationship between arterial stiffness and advancing age in a healthy population and reported that height was not sufficient to fully explain the higher reflected wave pressure in women in multivariable analyses. Kohara et $\mathrm{al}^{3}$ reported that the radial AIx is higher in women than in men, and the difference persists even after body height was adjusted. In contrast to these opinions, Smulyan et $a l^{8}$ showed that stiff aorta is related to short stature. Reeve et $\mathrm{l}^{10}$ reported that height is inversely and independently related to central hemodynamics after correction for traditional cardiovascular risk factor, regardless of sex difference.

In our study, radial AIx 75 and central PP are elevated in the shorter height group in both sexes. In the multiple regression analysis, only shorter height was an important factor
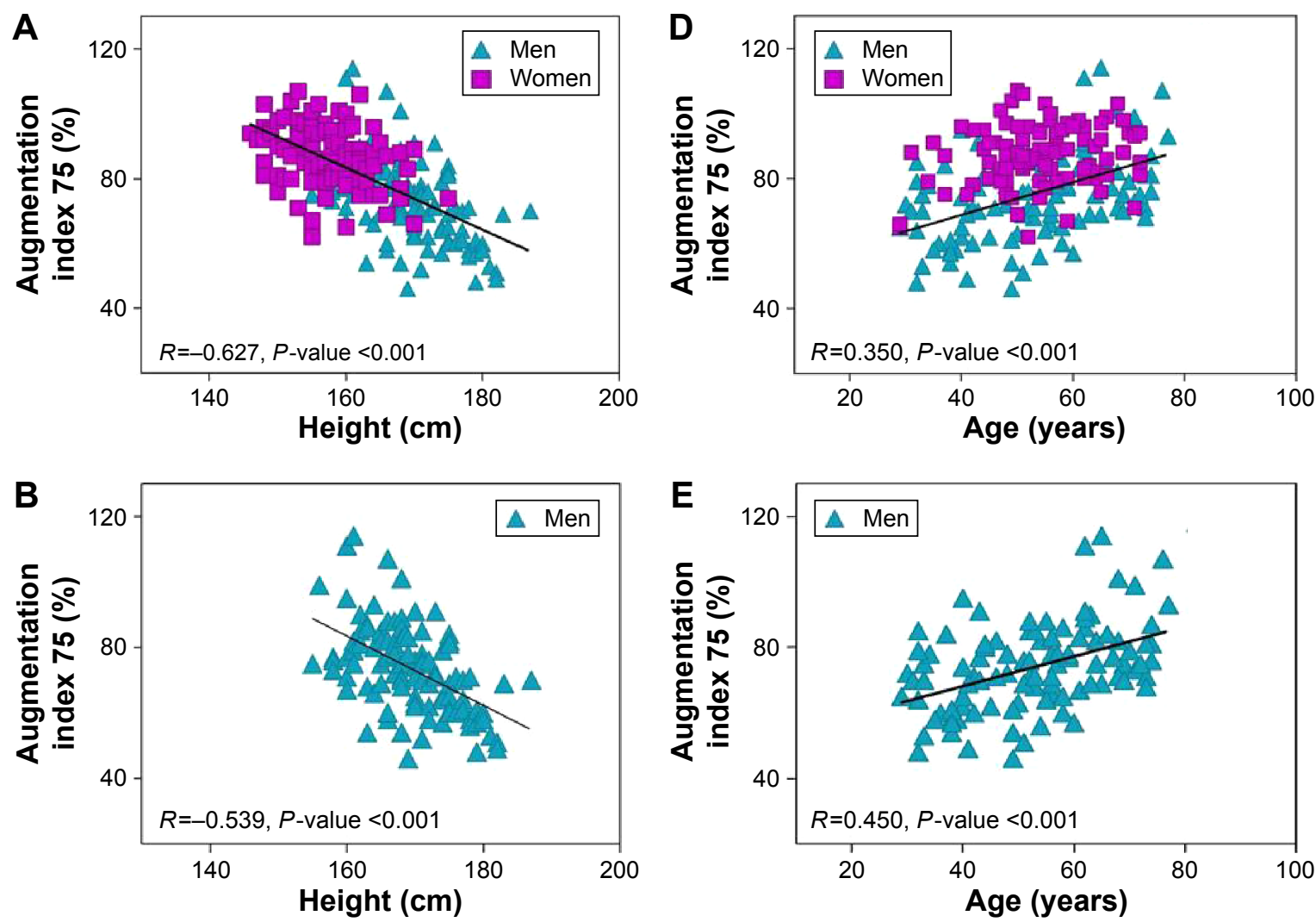

Figure 2 (Continued) 

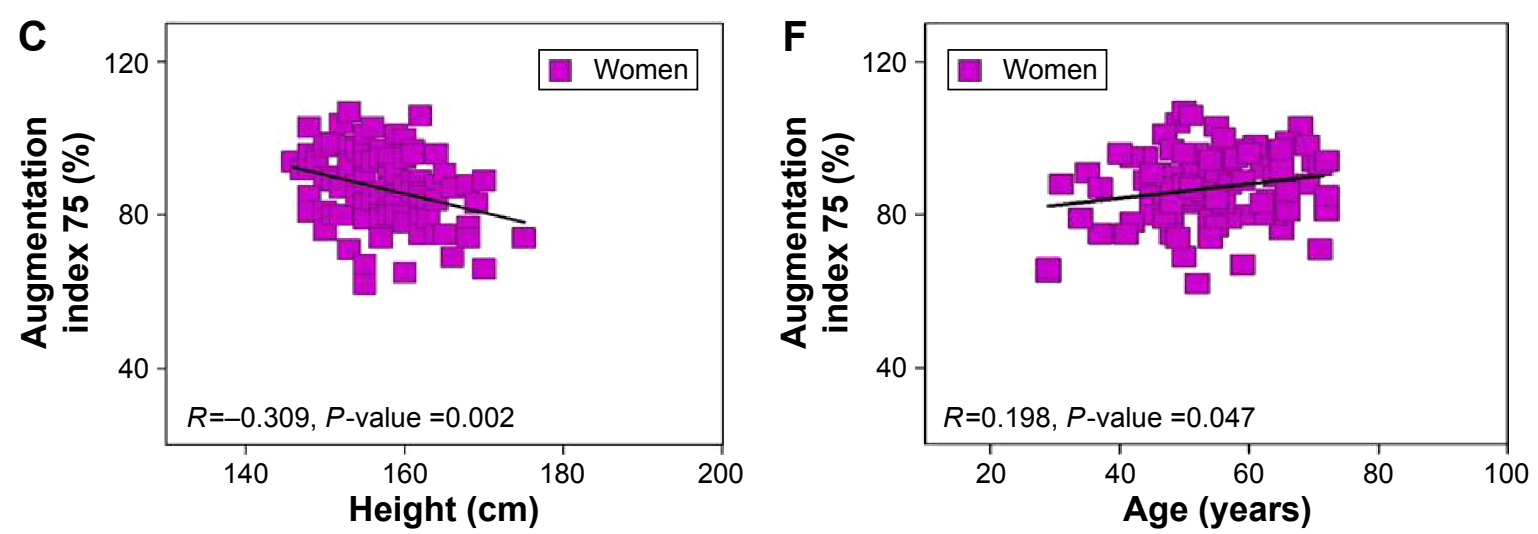

Figure 2 Pearson's correlation of Alx 75 with height and age in patients with hypertension.

Notes: (A and D) Alx 75 was shown to have inverse correlation with height and positive correlation with age in patients with hypertension. In the Pearson correlation and Hotelling test, the slope of the association between height and Alx 75 was significantly stronger than the slope of the association between age and Alx 75 ( $t=3.615$, $P$-value $=0.005$ ). (B and $\mathbf{C}$ ) In Pearson's correlation analysis using Fisher's Z-transformation, the slope of the association between height and Alx 75 showed no difference in men and women $(Z=I .191, P$-value $=0.222)$. $(E$ and $\mathbf{F})$ The slope of the association between age and $A l x 75$ was significantly stronger in men $(Z=I .994, P$-value $=0.043)$. Solid lines indicate the regression trend lines.

Abbreviation: Alx 75, augmentation index 75 .

Table 4 Multiple regression analysis for an Alx 75 and key variables with and without sex stratification

\begin{tabular}{|c|c|c|c|c|}
\hline Variables & $\beta$ coefficient & $95 \% \mathrm{Cl}$ & $P$-value & Adjusted $R^{2}$ \\
\hline All patients & & & & 0.428 \\
\hline Age (years) & 0.232 & 0.060 to 0.404 & 0.009 & \\
\hline Women & 6.237 & 1.480 to 10.995 & 0.011 & \\
\hline Height $(\mathrm{cm})$ & -0.632 & -0.929 to -0.335 & $<0.001$ & \\
\hline DM & -4.912 & -10.103 to 0.279 & 0.063 & \\
\hline Smoker & -0.363 & -5.750 to 5.023 & 0.894 & \\
\hline $\mathrm{HDL}(\mathrm{mg} / \mathrm{dL})$ & 0.025 & -0.092 to 0.142 & 0.671 & \\
\hline 24-hour ABPM day SBP $(\mathrm{mmHg})$ & 0.152 & 0.010 to 0.294 & 0.037 & \\
\hline 24-hour ABPM mean HR (beat/min) & -0.118 & -0.299 to 0.063 & 0.200 & \\
\hline EMBPS & -0.015 & -0.114 to 0.084 & 0.766 & \\
\hline Men & & & & 0.280 \\
\hline Age (years) & 0.296 & 0.054 to 0.538 & 0.017 & \\
\hline Height $(\mathrm{cm})$ & -0.789 & -1.247 to -0.330 & 0.001 & \\
\hline DM & -4.656 & -13.047 to 3.735 & 0.272 & \\
\hline Smoker & -1.147 & -7.845 to 5.552 & 0.734 & \\
\hline $\mathrm{HDL}(\mathrm{mg} / \mathrm{dL})$ & -0.004 & -0.223 to 0.215 & 0.970 & \\
\hline 24-hour ABPM day SBP $(\mathrm{mmHg})$ & 0.232 & -0.002 to 0.465 & 0.052 & \\
\hline 24-hour ABPM mean HR (beat/min) & 0.001 & -0.299 to 0.298 & 0.998 & \\
\hline EMBPS & -0.037 & -0.197 to 0.123 & 0.645 & \\
\hline Women & & & & 0.154 \\
\hline Age (years) & 0.019 & -0.248 to 0.287 & 0.886 & \\
\hline Height (cm) & -0.396 & -0.782 to -0.011 & 0.044 & \\
\hline DM & -6.640 & -13.266 to -0.014 & 0.050 & \\
\hline Smoker & 7.553 & -5.014 to 20.120 & 0.235 & \\
\hline $\mathrm{HDL}(\mathrm{mg} / \mathrm{dL})$ & 0.016 & -0.111 to 0.144 & 0.798 & \\
\hline 24-hour ABPM day SBP $(\mathrm{mmHg})$ & 0.032 & -0.145 to 0.208 & 0.722 & \\
\hline 24-hour ABPM mean HR (beat/min) & -0.276 & -0.507 to -0.046 & 0.020 & \\
\hline EMBPS & 0.036 & -0.101 to 0.173 & 0.601 & \\
\hline
\end{tabular}

Abbreviations: Alx 75, augmentation index 75; Cl, confidence interval; DM, diabetes mellitus; HDL, high-density lipoprotein; ABPM, ambulatory blood pressure monitoring; SBP, systolic blood pressure; HR, heart rate; EMBPS, early-morning blood pressure surge. 
Table 5 Simple linear regression analysis of radial Alx 75 and key variables

\begin{tabular}{lllll}
\hline Variables & $\beta$ coefficient & $\mathbf{9 5 \% ~ C l}$ & P-value & Adjusted $\boldsymbol{R}^{2}$ \\
\hline Age (years) & 0.399 & 0.250 to 0.547 & $<0.00$ I & 0.118 \\
Women & 13.130 & 9.962 to 16.267 & $<0.00$ I & 0.249 \\
Height (cm) & -0.944 & -1.107 to -0.78 I & $<0.00$ I & 0.390 \\
DM & -2.760 & -8.75 I to 3.231 & 0.365 & -0.001 \\
Smoker & -9.628 & -15.614 to -3.641 & 0.002 & 0.043 \\
LDL (mg/dL) & -0.36 & -0.103 to 0.030 & 0.279 & 0.003 \\
HDL (mg/dL) & 0.146 & 0.004 to 0.288 & 0.045 & 0.025 \\
Brachial SBP (mmHg) & 0.013 & -0.089 to 0.114 & 0.804 & 0.067 \\
24-hour ABPM day SBP (mmHg) & -0.067 & -0.220 to 0.087 & 0.392 & 0.001 \\
24-hour ABPM mean HR (beat/min) & -0.343 & -0.538 to -0.149 & 0.001 & 0.052 \\
Central SBP (mmHg) & 0.398 & 0.323 to 0.473 & $<0.001$ & 0.350 \\
EMBPS (mmHg) & 0.114 & 0.005 to 0.222 & 0.040 & 0.016 \\
Dipping (\%) & 0.043 & -0.206 to 0.293 & 0.733 & 0.001 \\
\hline
\end{tabular}

Abbreviations: Alx, augmentation index; Cl, confidence interval; DM, diabetes mellitus; LDL, low-density lipoprotein; HDL, high-density lipoprotein; SBP, systolic blood pressure; ABPM, ambulatory blood pressure monitoring; HR, heart rate; EMBPS, early-morning blood pressure surge.

of elevated radial AIx 75, regardless of sex. However, the adjusted $R^{2}$ of women was lower than that of all patients in the multiple regression analyses, and thus, these results imply that the shorter height has less influence on the elevation of radial AIx 75 in women than it does in men; sex difference is significantly related to the elevation of radial AIx 75.

With shorter height, the reflected wave is transmitted faster and arrives in systole, resulting in augmentation of systolic pressure, increased cardiac workload, loss of augmentation of diastolic pressure, and decreased coronary perfusion. Finally, AIx reflects the overall interaction between the arterial tree and the left ventricle. In addition, increased AIx could deteriorate cardiac function and arterial stiffness. Moreover, sex difference is important in affecting the elevation of AIx. Women had larger reflected waves than men, because of shorter height and closer physical proximity between the heart and reflecting sites. ${ }^{14}$ Mismatch between femoral-to-abdominal aortic dimension also contributes to the elevation of augmentation pressure in women. ${ }^{21}$ The smaller diameter of the radial artery and higher pulse wave velocity in women has also been reported to account for the higher AIx in women. ${ }^{22}$

These physical differences and the mismatch of arterial dimension would result in change of AIx between men and women. Hormonal effect could also influence the elevation of augmentation pressure in women. There are some reports on the unfavorable effect of a lack of estrogen due to menopause, as well as the favorable effects of administered estrogen. The absence of estrogen in older women could contribute to the elevation of SBP. ${ }^{8,23,24}$ Although we did not check the menopausal state of women, the mean age of women was
54 years; so, many postmenopausal women have probably been recruited in our study.

Peripheral BP parameters were obtained from 24-hour ABPM (different from other study), as they represent the circadian variation of the reported variables, which is better than the single measurement. ${ }^{25}$ Especially, EMBPS was significantly different between shorter height group and taller height group in men. Twenty-four-hour ABPM parameters might be related with height, aging, and sex difference.

The results of this study were similar to those of earlier studies that reported the link between central hemodynamics and height and sex. What is different from those data is that we analyzed patients with newly diagnosed hypertension who had no history of taking any antihypertensive agents. We collected patients with relatively low cardiovascular risk. It is evident that sex and height play an important role in changing the arterial stiffness in our study.

\section{Limitations}

We did not evaluate the relationship between height and cardiovascular mortality. This study is retrospectively evaluated and has a small sample size. There were significant differences in baseline clinical characteristics according to the sex and height differences. As we included only Korean patients, the ethnic character might influence our results. We did not identify menopausal status of women.

\section{Conclusion}

In this study of patients with never-treated hypertension, shorter height and sex difference are the important risk factors for elevated radial AIx 75, in addition to aging. 


\section{Acknowledgments}

This research was supported by Basic Science Research Program through the National Research Foundation of Korea (NRF) funded by the Ministry of Education (NRF2014R1A6A1029617) and Chungnam National University Hospital Research Fund.

\section{Disclosure}

The authors report no conflicts of interest in this work.

\section{References}

1. Vlachopoulos C, Aznaouridis K, O’Rourke MF, Safar ME, Baou K, Stefanadis C. Prediction of cardiovascular events and all-cause mortality with central haemodynamics: a systematic review and meta-analysis. Eur Heart J. 2010;31(15):1865-1871.

2. Vlachopoulos C, Aznaouridis K, Stefanadis C. Prediction of cardiovascular events and all-cause mortality with arterial stiffness: a systematic review and meta-analysis. J Am Coll Cardiol. 2010;55(13): 1318-1327.

3. Kohara K, Tabara Y, Oshiumi A, Miyawaki Y, Kobayashi T, Miki T. Radial augmentation index: a useful and easily obtainable parameter for vascular aging. Am J Hypertens. 2005;18(Suppl 1):11S-14S.

4. Rich-Edwards JW, Manson JE, Stampfer MJ, et al. Height and the risk of cardiovascular disease in women. Am J Epidemiol. 1995; 142(9):909-917.

5. Lee CM, Barzi F, Woodward M, et al. Adult height and the risks of cardiovascular disease and major causes of death in the Asia-Pacific region: 21,000 deaths in 510,000 men and women. Int J Epidemiol. 2009; 38(4):1060-1071.

6. Weber T, Auer J, O'Rourke MF, et al. Increased arterial wave reflections predict severe cardiovascular events in patients undergoing percutaneous coronary interventions. Eur Heart J. 2005;26(24):2657-2663.

7. Smulyan H, Marchais SJ, Pannier B, Guerin AP, Safar ME, London GM. Influence of body height on pulsatile arterial hemodynamic data. J Am Coll Cardiol. 1998;31(5):1103-1109.

8. Smulyan H, Asmar RG, Rudnicki A, London GM, Safar ME. Comparative effects of aging in men and women on the properties of the arterial tree. J Am Coll Cardiol. 2001;37(5):1374-1380.

9. Gertler MM, Garn SM, White PD. Young candidates for coronary heart disease. J Am Med Assoc. 1951;147(7):621-625.

10. Reeve JC, Abhayaratna WP, Davies JE, Sharman JE. Central hemodynamics could explain the inverse association between height and cardiovascular mortality. Am J Hypertens. 2014;27(3):392-400.

11. Németh ZK, Studinger P, Kiss I, et al. The method of distance measurement and torso length influences the relationship of pulse wave velocity to cardiovascular mortality. Am J Hypertens. 2011;24(2):155-161.
12. Weber T, Auer J, O'Rourke MF, et al. Arterial stiffness, wave reflections, and the risk of coronary artery disease. Circulation. 2004; 109(2):184-189.

13. Shim CY, Park S, Choi D, et al. Sex differences in central hemodynamics and their relationship to left ventricular diastolic function. $\mathrm{J} \mathrm{Am} \mathrm{Coll}$ Cardiol. 2011;57(10):1226-1233.

14. Mitchell GF, Parise H, Benjamin EJ, et al. Changes in arterial stiffness and wave reflection with advancing age in healthy men and women: the Framingham Heart Study. Hypertension. 2004;43(6):1239-1245.

15. Haensel A, Utech K, Langewitz W. Validation of TONOPORT V blood-pressure measuring monitor in adults. J Hum Hypertens. 2005; 19(9):745-749.

16. Franssen PM, Imholz BP. Evaluation of the Mobil-O-Graph new generation ABPM device using the ESH criteria. Blood Press Monit. 2010;15(4):229-231.

17. Ding F-H, Fan W-X, Zhang R-Y, Zhang Q, Li Y, Wang J-G. Validation of the noninvasive assessment of central blood pressure by the SphygmoCor and Omron devices against the invasive catheter measurement. Am J Hypertens. 2011;24(12):1306-1311.

18. Williams B, Lacy PS, Thom SM, et al. Differential impact of blood pressure-lowering drugs on central aortic pressure and clinical outcomes principal results of the Conduit Artery Function Evaluation (CAFE) Study. Circulation. 2006;113(9):1213-1225.

19. Roman MJ, Devereux RB, Kizer JR, et al. Central pressure more strongly relates to vascular disease and outcome than does brachial pressure: the Strong Heart study. Hypertension. 2007;50(1):197-203.

20. Cho SK, Cho SK, Kim KH, et al. Impacts of age on arterial stiffness and blood pressure variables in patients with newly diagnosed untreated hypertension. Korean Circ J. 2015;45:44-50.

21. Cecelja M, Jiang B, McNeill K, et al. Increased wave reflection rather than central arterial stiffness is the main determinant of raised pulse pressure in women and relates to mismatch in arterial dimensions: a twin study. J Am Coll Cardiol. 2009;54(8):695-703.

22. Gatzka CD, Kingwell BA, Cameron JD, et al. Gender differences in the timing of arterial wave reflection beyond differences in body height. J Hypertens. 2001;19(12):2197-2203.

23. Staessen JA, Ginocchio G, Thijs L, Fagard R. Conventional and ambulatory blood pressure and menopause in a prospective population study. J Hum Hypertens. 1997;11(8):507-514.

24. Szekacs B, Vajo Z, Acs N, et al. Hormone replacement therapy reduces mean 24-hour blood pressure and its variability in postmenopausal women with treated hypertension. Menopause. 2000;7(1):31-35.

25. Bassareo PP, Marras AR, Pasqualucci D, Mercuro G. Increased arterial rigidity in children affected by Cushing's syndrome after successful surgical cure. Cardiol Young. 2010;20(6):610-614.
Clinical Interventions in Aging

\section{Publish your work in this journal}

Clinical Interventions in Aging is an international, peer-reviewed journal focusing on evidence-based reports on the value or lack thereof of treatments intended to prevent or delay the onset of maladaptive correlates of aging in human beings. This journal is indexed on PubMed Central, MedLine,

\section{Dovepress}

CAS, Scopus and the Elsevier Bibliographic databases. The manuscript management system is completely online and includes a very quick and fair peer-review system, which is all easy to use. Visit http://www.dovepress. com/testimonials.php to read real quotes from published authors. 